\title{
Information in practice
}

\section{Cancer patients' information needs and information seeking behaviour: in depth interview study}

\author{
Geraldine M Leydon, Mary Boulton, Clare Moynihan, Alison Jones, Jean Mossman, \\ Markella Boudioni, Klim McPherson.
}

\begin{abstract}
Objectives To explore why cancer patients do not want or seek information about their condition beyond that volunteered by their physicians at times during their illness.

Design Qualitative study based on in-depth interviews.

Setting Outpatient oncology clinics at a London cancer centre.

Participants 17 patients with cancer diagnosed in previous 6 months.

Main outcome measures Analysis of patients' narratives to identify key themes and categories. Results While all patients wanted basic information on diagnosis and treatment, not all wanted further information at all stages of their illness. Three overarching attitudes to their management of cancer limited patients' desire for and subsequent efforts to obtain further information: faith, hope, and charity. Faith in their doctor's medical expertise precluded the need for patients to seek further information themselves. Hope was essential for patients to carry on with life as normal and could be maintained through silence and avoiding information, especially too detailed or "unsafe" information. Charity to fellow patients, especially those seen as more needy than themselves, was expressed in the recognition that scarce resources-including information and explanations-had to be shared and meant that limited information was accepted as inevitable. Conclusions Cancer patients' attitudes to cancer and their strategies for coping with their illness can constrain their wish for information and their efforts to obtain it. In developing recommendations, the government's cancer information strategy should attend to variations in patients' desires for information and the reasons for them.
\end{abstract}

\section{Introduction}

Over recent years, communication and information have increasingly been considered important in helping people to cope with cancer. ${ }^{1-6}$ A diagnosis of cancer may invoke uncertainty, fear, and loss that can be alleviated by information. ${ }^{7-9}$ Research has indicated that the vast majority of cancer patients want to be informed about their illness. ${ }^{5}$ However, it is also recog- nised that patients vary in how much information they want and that this may change during their illness. These attitudes are reflected in the efforts that patients make to obtain further information or to resist information that is offered to them. ${ }^{10}$ In 1980 Ingelfinger, at that time an oncologist and editor of the New England Journal of Medicine, reported that when he discovered he had cancer he did not want all available information nor to have to face the uncertainties of the different treatment choices offered to him. ${ }^{11}$ This hints at the complexity of providing information in oncology; information may be ignored or avoided by patients, regardless of their prior knowledge or occupation.

For those who provide care to cancer patients, the challenge is finding a way of providing information that is appropriate for patients who may benefit from knowing something about their illness and its treatment but may not wish to know everything about it at all times. This is particularly important in the light of the government's current commitment to build on the work of the Calman-Hine Expert Advisory Group to improve cancer care. ${ }^{12}$ Recent developments include plans for a national cancer information strategy, the details of which have yet to be agreed. It is likely that such an initiative could include "core information packages" for all patients (NHS Information Authority, draft consultation document of cancer information strategy). In light of the move toward more formal provision of information, there is an urgent need to understand the ways that and the reasons why patients may choose not to seek or may resist further information about their cancer. This paper reports the findings of a study that explored patients' reasons for not wanting further information.

\section{Participants and methods}

Between November 1998 and February 1999, three physicians from a cancer centre identified patients whose cancer had been diagnosed in the previous six months and who were judged well enough to be interviewed. The first 24 patients who met these criteria were asked to participate in our study. Four of the patients declined (three men), and three others (two men) were too ill to be interviewed on the day of the appointment. Our study was approved by the ethics committee of the study site.
Cancer and Public Health Unit, Department of Epidemiology and Population Health, London School of Hygiene and Tropical Medicine, London

WC1E 7HT

Geraldine M

Leydon

research fellow in

cancer

Klim McPherson professor of public health epidemiology

School of Social

Sciences and Law, Oxford Brookes University, Oxford OX3 0BP

Mary Boulton professor of sociology Institute of Cancer Research and the Royal Marsden

NHS Trust, Sutton SM2 5PT

Clare Moynihan medical sociologist

Royal Free Hospital School of Medicine Royal Free Hospital, London

NW3 2QG

Alison Jones consultant in oncology

CancerBACUP,

3 Bath Place,

London EC2A 3JR

Jean Mossman

chief executive

Markella Boudioni research officer

Correspondence to: G M Leydon

g.leydon@

lshtm.ac.uk

BMJ 2000;320:909-13 
Sociodemographic data were collected via a brief pre-interview questionnaire. In-depth interviews, focusing on the patients' experiences of information about their illness from first symptoms through to diagnosis and treatment, were carried out in the patient's home or the hospital. Each lasted between 45 and 90 minutes. Interviews were audiotaped, transcribed, and analysed according to the methods of framework analysis. ${ }^{13}$ Developed by a specialist qualitative research unit called Social and Community Planning Research, framework analysis involves a systematic process of "sifting, charting and sorting material according to key issues and themes."13 Transcripts were read repeatedly to identify the key themes and categories, which were then developed into a framework for coding the body of interview data. Multiple coding by GML, M Boulton, and CM tested the acceptability and reliability of the designated categories, and the validity of the coding was checked through deviant case analysis. ${ }^{14}$

\section{Results}

\section{Sample characteristics}

Of the 17 patients who completed the interview, 11 were women and six were men; 10 were non-manual workers, three were manual workers, and four were not classified; and 10 were white British, five were white other, and two were black British. Their median age was 55 years (range 28-79). The primary cancer diagnosed was breast cancer (4 cases), lymphoma (4), non-Hodgkin's lymphoma (2), lung cancer (2), and one case each of cancer of the colon, bladder, skin, brain, and liver. Two patients had a history of cancer.

\section{Information about cancer and its treatment}

All 17 patients interviewed had wanted basic information about diagnosis, treatment options, and common side effects of treatment. However, the timing of the desire for this information varied, as did the level of detail and content. Six patients had made efforts to obtain as much information as possible, but the remaining 11 patients reported minimal efforts to obtain information additional to that offered by hospital staff. All the interviews revealed a variability in attitude towards further information: patients did not want information about everything all of the time, but, at different times since their diagnosis, had wanted more or less information about particular aspects of their condition and its treatment.

Patients' attitudes towards seeking or accepting further information were based on their attitude to the management of their cancer. Systematic analysis of patient narratives revealed three overarching attitudes associated with a limited desire for and use of further information: faith, hope, and charity. Elements of faith, hope, and charity were present in all transcripts and affected information need and information seeking behaviour differently at different times.

\section{Faith}

To differing degrees, patients displayed faith in their doctors, and this contributed to their attitude toward seeking information beyond that volunteered by health professionals in routine interactions. Often such faith

\section{Box 1: Faith}

1. "I didn't know what to expect with the treatment, I was optimistic. I couldn't even think about how I could do chemotherapy. I prepared my mind for whatever it takes, [to] follow the rules of the experts; they have said that this is what I've go to do to get better, and I've got to-whatever way, shape, or form-get better." (Interview 10: 45 year old man with lymphoma) 2. "To be honest, when they said to me it's cancer I thought I'll put it in their hands now because sometimes it can be a dangerous thing when you start listening and looking. We only have a certain amount of intellect, and we only have a certain amount of education. There is nothing like an ignorant man trying to learn and know every little thing about it. With regards to medicine and the like, the less you know the better." (Interview 12: 74 year old man with skin cancer)

3. "Maybe they don't tell you everything-all the side effects-because they think it will frighten you. But if you read it yourself they probably think, 'Clever dick,' for finding out. They probably think, 'She should be listening to us.' I don't think they particularly like you bringing up ideas, not that much, not really." (Interview11: 64 year old woman with brain cancer)

4. "I don't want to use information lines and things like that at the moment. I'm working on my principle that ignorance is bliss. I am not denying the situation I am in, but I am not speaking to people like that at the moment, I don't feel I need to. At the moment I get what I want, but not too much detail. Further down the line it may change, depending on which way it goes, if it's bad." (Interview 5: 44 year old man with liver cancer, melanoma of the eye seven years earlier)

reflected an understanding of the complexity and medical uncertainty surrounding cancer and its treatment and ultimately reflected a will to live (see box 1 , quote 1). Belief in the maxim that "doctor knows best" sometimes negated the perceived value of additional information, and patients believed (and some found) that additional information could confuse their situation. Having faith in their doctors' ability to successfully deploy what were often perceived as impressive and modern medical technologies often precluded information seeking.

Faith was clearly linked with the view that medical knowledge was difficult to understand. This was particularly the case among older patients, who, because they felt their knowledge and understanding of medicine was limited, believed that additional searching could be dangerous and exacerbate an already difficult situation (box 1, quote 2).

Some, who spoke of their faith in their doctors' expertise, expressed concern that information seeking might be perceived as transgressing their incumbent role as patient. Being a good patient was construed as "doing as you are told" and being a "good customer," as opposed to knowing a lot and being inquisitive (box 1, quote 3). For most patients, this perception of themselves as apparently disempowered was rationalised and placed in a favourable light by relying on and having faith in their doctors' expertise. For most, placing their faith in their doctors' hands was a strategy that could change at a later stage depending on various factors, including the course of the disease and the need to maintain a sense of hope (box 1, quote 4). 


\section{Hope}

A sense of hope pervaded all 17 narratives, and for some this was closely linked to fear. Patients created a facade of hopefulness, often in the most advanced cases (box 2, quote 1). Hope was indispensable for survival, and this interacted with information seeking in a complex way. For some it meant avid searching for information, particularly about alternative treatments, but for others it meant limited searching for or even avoidance of new information. Immediately after diagnosis, patients needed to be enabled to ask questions and search for information; without basic diagnostic information, attempts to find out additional information were often thwarted (box 2, quote 2).

At different times during their illness patients halted their information seeking because of fearful and contradictory information, often a consequence of genuine medical uncertainties. These periods of self censorship functioned to preserve hope by avoiding negative information about their illness and in turn helped to manage their fears associated with the potential of a negative outcome (see box 2, quote 3 ).

Contradictory information was a source of anxiety for most patients, as it often confused treatment decisions already made. Weighing evidence and deciding on the best course of action was difficult, even with a medical background. Depending on the immediacy of the issue, some patients resolved the conflict of contradictory information by calling on other patients and lay contacts (including medical friends) to judge between conflicting accounts (box 2, quotes 3 and 4).

Women patients often valued the knowledge and experience of other cancer patients more than medical information, and this personal experience often proved invaluable with treatment decision making. By contrast, the men rarely spoke of relying on the experience of other patients; once they left the outpatient clinic or treatment room they preferred a policy of "life as normal" in which cancer could be forgotten (at least superficially).

Additional information could exacerbate fear and threaten to undermine patients' hopes. Even basic introductory booklets could be frightening, and consequently some patients truncated their efforts to find out more (box 2, quotes 2 and 5). Patients were also aware that literature produced for patients "in general" was not necessarily relevant to every individual, and the difficulty of discerning information germane to their own individual situations was clearly frustrating (box 2 , quote 6).

To avoid the risk of uncovering information that could threaten their hope, some enlisted the help of others in finding out new material. Not everyone had access to proxy informants, however, and those too fearful to assimilate additional information avoided all information sources. Emotive media coverage of "cancer victims" such as Linda McCartney rendered avoidance difficult at times and for some constituted an unwelcome threat to hope (box 2, quote 7).

The expression of hope often entailed presenting a brave face to others, and this could itself make it difficult to talk about or seek information regarding cancer. Getting on with life and maintaining a positive outlook was perceived as the approach to managing illness that was most respected by hospital staff, friends, and family. Asking for information beyond the basic details of

\section{Box 2: Hope}

1. "Fortunately, I've got the slow growing one; the counsellor drew a diagram for me (shows diagram to GML). So she said there was the tumour there [breast], there's the other one there [lung], and then they found a very small one on the top [brain]. So I could actually feel where everything was, which was good, but then also in the fluid going round the brain and down the spinal cord. The doctor said there are other [treatments] if this one doesn't work, so the way I am looking at it is it's either going to be good, and I don't know what happens after that, or if it isn't there are other options. Where there are other options, there is still hope." (Interview 3: 54 year old woman with primary breast cancer and multiple metastases)

2. "I found out what I had by reading my notes on the way up to $x$ ray. A high or low grade, T or B cell lymphoma. It's no good anyway, because I don't know the difference. Information is difficult in the beginning because I couldn't look at the relevant bits, so it's better to be told your exact diagnosis as soon as possible, otherwise even general booklets are too scary and too detailed-my boyfriend looks for me." (Interview 2: 28 year old woman with non-Hodgkin's lymphoma)

3. "In the end I got so confused and one woman had such an influence on me that I was moving very fast in the direction of thinking I would have chemotherapy, and I wasn't too keen to get too much input that was going to suggest I shouldn't. I think I consciously censored myself. I didn't look chemotherapy up on the internet; I just have recently, and it's really shaken me." (Interview 1: 48 year old woman with breast cancer)

4. "It's very difficult making treatment decisions because of the contradictory information, and it's very difficult not being a medical person. It was this woman in the end who helped me decide. She didn't try to persuade me, but it was something about the reasons she gave, you know, regretting not doing it in the future if I get cancer again. Secretly I think I knew I was going to do it [have chemotherapy], and I didn't want to find out too much negative information." (Interview 1: 48 year old woman with breast cancer) 5. "The thing with these leaflets-I mean, I did start to read a few, but then when you read them you get information, but I think they give you a bit too much about what it's going to do and where it can go. I know I have it, and that's all I want to know." (Interview 9: 60 year old man with liver cancer)

6. "I was trying to find information about what treatments are available and things like that, but I kept on finding that every person is different, so I found that trying to find out the different grades and things was difficult. I don't think you can find an answer actually that will satisfy you .... I think I've found my way of coping through God-just pray, pray, pray." (Interview 4: 46 year old woman with breast cancer)

7. "Trouble was I used to buy a newspaper every day in hospital, and every day cancer-always somebody who had bravely died of cancer. I was a bit cross, and I nearly wrote to the [newspaper] because it was every day, and I thought, 'Well, what about all those people who bravely live?" (Interview 6: 64 year old woman with non-Hodgkin's lymphoma)

8. "Friends and family expect you to be depressed and talk about it, but if you're all doom and gloom people won't want to come near you, and you need people. This is why you tend to switch off a bit and just have a bloody good laugh when people come to see you, because then they'll want to come back to see you." (Interview 3: 54 year old woman with primary breast cancer and multiple metastases)

the diagnosis and side effects of treatment could undermine patients' positive appearance. The pressure to present a hopeful facade also related to a fear of using up any reserve of sympathy and support from friends and relatives (box 2, quote 8).

The pressure to preserve a brave face and the linked pressure to avoid information about the illness was more common among men, who maintained hope through silence. Men in particular preferred not to ask questions of the medical profession, or people in their wider social networks, so as to avoid discussions of disease recurrence and, ultimately, death. Efforts to maintain hope could thus drive out interest in finding out further information. 


\section{Charity}

Even in the face of their adversity, all the patients reported having been influenced by thoughts of others whom they perceived to be worse off or more needy than themselves. As with other NHS resources, information-or access to those who could provide it-was seen as a limited resource, rationed among all patients (box 3, quote 1).

Frequent references were made to the usefulness of the clinic consultation for getting reassurance, which was vital for maintaining hope, and obtaining help in interpreting additional information from independent sources. None the less, patients expressed concern about taking up too much of their doctors' time when other patients were waiting to be seen in the outpatient clinic (box 3, quote 2). These sentiments were more evident among those patients with close friends or family (most of our sample), who perceived patients without such support to be more needy and deserving of information (box 3, quote 3).

By making comparisons with others, patients could see that their situation was better than that of others. However, this favourable comparison could then be seen as weakening their claim for scarce resources and giving precedence to the claim of others.

Some found it easier to accept information obtained by friends and relatives because they had not personally used a scarce resource. Similarly, patients clearly found information easier to accept when it was verbally offered by hospital staff rather than having to ask for additional information themselves. Others, however, pointed to the legitimate needs of their fellow patients in explaining their reluctance to make further demands on the time and resources of doctors and nurses in the clinics.

\section{Discussion}

We have investigated an observation commonly made by those who provide care to cancer patients, that not all patients want extensive information about their condition and treatment at all stages of their illness. Though

\section{Box 3: Charity}

1. "I got information on home nursing, and they came round, but I stopped them in the end. Not because I didn't want them, but, after I started on my chemotherapy, they used to pop around to see how I was, but I seemed to be doing okay ... so I said to them it's best to just 'phone me. I said there's probably other people who needed to see them more than me." (Interview 9: 58 year old man with liver cancer)

2. "The consultant said, 'Have you got any questions?' and I had, but I felt that there was this huge waiting room filled with people. I had written them down, but I then felt very conscious of the fact that the consultant had this enormous pressure of people outside. There was a lot of talk among the nurses about how many people there were, so I knew I had to rush." (Interview 1: 48 year old woman with breast cancer)

3. "I haven't used telephone lines or anything like that. I have support from the family, and there are people who have got nobody at all, so why should I bother them when I've got people that I can call on?' (Interview 12: 74 year old man with skin cancer) not based on a statistically representative sample, this study provides insights into the reasons underlying patients not seeking information at particular times during their illness within six months of diagnosis.

\section{Limitations of study}

Qualitative methods often dictate small samples, and personal interviews could skew the sample towards patients who find it easier to talk about their illness. The constraints imposed on the recruitment process by the setting of a busy clinic in a cancer centre meant that it would have been impossible to sample purposively. Fortunately, however, the final sample comprised patients with a range of sociodemographic backgrounds, cancer types, and experiences of illness. The similarities between some of our core themes and those found in other studies ${ }^{10}$ permits confidence in the validity of our data and analysis of the data.

A longitudinal, prospective study could avoid the limitations of single retrospective interviews. A longitudinal approach could also maximise the ability to explore and map out the fluid and changing nature of patients' orientations to the management of their cancer and their subsequent efforts to obtain (and avoid) additional illness information over time. A survey study to assess the generalisability of some of the key findings from this interview study, in particular the determinants of information preference and access to information, such as gender and age, will be reported at a later date.

\section{Reasons for not seeking information}

Our study shows that in our apparently "patient centred" era some patients (particularly older patients and men) still adopt a non-participatory role in the management of their illness. ${ }^{15}{ }^{16}$ In the 1950 s Parsons argued that the nature of the roles of patients derived from the faith placed in doctors' medical expertise. ${ }^{17}$ These perceptions still exist and influence patients' need for and seeking of information. Wanting to be seen as a "good customer," trusting what a doctor says, and "ignorance" and the consequent (perceived) inability to assimilate medical information are important reasons for patients' non-use of information. Arguably, older patients would have grown up in an era characterised by "doctor centred" practice, ${ }^{18}$ and this may help to explain the greater use of independent information services by younger patients. ${ }^{19}{ }^{20}$

Men seemed to be less likely to access additional information services, and the next phase of our research will focus on these sex differences. Men maintained hope through silence and, more generally, "strength in silence" (C Moynihan et al, "Strength in silence: men and cancer," British psychosocial oncology conference, Royal College of Physicians, London, 1999), and this influenced their desire for information at different times during their illness. The value of hope in the management of chronic illness is well established, ${ }^{21}{ }^{22}$ but our study has shown the complexity of the relationship between hope and a patient's desire for information. ${ }^{23}$ Hope and fear are intertwined, and patients oscillate between the desire for more information and the avoidance of new information. Hope might be accomplished and maintained through silence, periods of self censorship, and not searching for information or searching by proxy, and these 
strategies enable patients to circumvent negative information about their illness, which poses a constant threat to hope. As Ruth Pinder found in her study of Parkinson's disease, "knowledge of what the clinical facts mean is not always the priceless resource other writers [suggest]. Sometimes it is too threatening." ${ }^{10}$

Finally, we found that patients' behaviour was influenced by consideration of the needs of other patients. This attitude of charity reflected patients' perceptions of a rationed health service and helped to rationalise their having minimal information. This attitude has received little attention in the context of cancer patients (S Morris, medical sociology conference, York, 1998) and should become an increasingly important consideration as rationing becomes more widely acknowledged in the NHS.

Patients' preferences for information derives from the coping strategy or attitude they have to managing their cancer. While all patients have the right to information, they will wish to use this right to varying degrees at different times. Health service providers need to continuously assess whether each individual patient wants only limited information or whether external constraints such as a language barrier, clinic organisation, or the attitudes of health professionals deny them access to the information they want.

\section{Conclusions}

The factors affecting patients' uptake of information services are complex. Patients' orientations toward faith, hope and charity may mean, at points on the illness path they may prefer to avoid disease related information and may choose not to use cancer information services. An understanding of the reasons why patients may want only limited information can help to ensure that the national strategy being developed is flexible and responsive to individual's coping strategies and information choices.

We thank all those who participated in the interviews and their physicians who facilitated recruitment, the Cancer Research Campaign for funding the study, Dr Judith Green for valuable discussions, and the Steering Committee for their dedication to the project.

Contributors: GML had the original idea for the study, and GML, KMcP, and M Boulton designed the protocol. GML conducted the literature review. GML and AJ recruited the patients. GML conducted the interviews. GML, CM, and M Boulton analysed the data and wrote the paper, and all authors contributed to the final draft of the paper. GML and $\mathrm{KMcP}$ are guarantors for the paper.

Funding: The Cancer Research Campaign (Psychosocial Committee).

Competing interests: None declared.

1 Cassileth B. Information and participation preferences among cancer patients. Ann Intern Med 1980;92:832-6.

2 Fallowfield L, Ford S, Lewis S. No news is not good news: information preferences of patients with cancer. Psycho-oncology 1995;4:197-202.

3 Coulter A. Evidence based patient information. BMJ 1998;317:225-6.

4 Ford S, Fallowfield L, Lewis S. Doctor-patient interactions in oncology. Soc Sci Med 1995;00:1-9.

5 Meredith C, Symonds P, Webster L, Lamont D, Pyper E, Gillis CR, et al. Information needs of cancer patients in West Scotland: cross sectional survey of patients' views. BMJ 1996;313:724-6.

6 National Cancer Alliance. Patient-centred cancer services? what patients say. Oxford: 6 National Cancer Alliance, 1996.

7 Houts P, Rusenas I., Simmonds M, Hufford D. Information needs of families of cancer patients: a literature review and recommendations. J Cancer Educ 1991;6:225-61.

8 Fallowfield LJ, Hall A, Maguire GP, Baum M. Psychological outcomes of different treatment policies in women with early breast cancer outside a clinical trial. BMJ 1990;301:575-80.

9 Butow P, Dunn S, Tattersall M, Jones Q. Computer-based interaction analysis of the cancer consultation. Br I Cancer 1994;71:1115-21.

10 Pinder R. The management of chromic illness. London: Macmillan,1990.

\section{What is already known on this topic}

Although cancer patients want to be informed about their illness, not all patients want extensive information about their condition and treatment at all stages of their illness

The reasons why patients vary in how much information they want have been little explored

\section{What this study adds}

In-depth interviews with 17 cancer patients showed they had three overarching attitudes to their cancer and strategies for coping with it that limited their wish for further information: faith, hope, and charity

Faith in doctors' medical expertise precluded the need for further information; hope was considered essential for coping and could be maintained by avoiding potentially negative information; and charity to fellow patients included the recognition that scarce resources (including information and explanations) had to be shared and meant that limited information was accepted as inevitable

11 Ingelfinger FJ “Arrogance” N Engl J Med 1980;303:1507-11.

12 Expert Advisory Group on cancer to the chief medical officers of England and Wales. A policy framework for commissioning cancer services. London: Department of Health, 1995

13 Ritchie J, Spencer L. Qualitative data analysis for applied policy research. In: Bryman A, Burgess R, eds. Analysing qualitative data. London: Routledge, 1994:172-94.

14 Silverman D. Interpreting qualitative data. London: Sage, 1993.

15 Lupton D. Your life in their hands: trust in the medical encounter. In: James V, Gave J, eds. Health and the sociology of emotions. Oxford: Blackwell, 1996:157-72.

16 Harrison J, Maguire P, Pitceathly L. Confiding in crisis: gender differences in patterns of confiding among cancer patients. Soc Sci Med $1995 ; 41: 1255-60$

17 Parsons T. The social system. New York: Free Press, 1951.

18 Byrne P, Long B. Doctors talking to patients. London: Department of Health and Social Security, 1976.

19 Boudioni M, McPherson K, Mossman J, Boulton M, Jones AL, King J, et al. An analysis of first-time enquirers to the CancerBACUP information service: variations with cancer site, demographic status and geographical location. Br J Cancer 1999;79:138-45.

20 Slevin ML, Nichols SE, Downer SM, Wilson P, Lister TA, Arnott S, et al. Emotional support for cancer patients: what do patients really want? Br J Cancer 1996;74:1275-9.

21 Wong-Wylie G, Jeune RF. Patient hope: exploring the interactions between physicians and HIV seropositive individuals. Qualitative Health Res 1997;7(1):32-56.

22 Orne M. On the nature of effective hope. Int J Psychiatry 1968;5:403-10.

23 Boudioni M, Mossman J, Jones AL, McPherson K, Leydon G. Celebrity's death from cancer resulted in increased calls to CancerBACUP. BMy 1998;317:1016.

(Accepted 19 January 2000)

\section{Corrections and clarifications}

\section{Obituaries}

The original wording of Dr Maureen Seddon's obituary (4 March, p 652) mentioned her patience in dealing with the "most troubled families." We apologise that in the editing process this was foolishly translated into the "most troublesome families."

A wrong date crept into the obituary of Dr William Deane Steele (5 February, p 385). He settled in Worcester in 1931, not 1928.

Gout

Some terminology in this editorial by R D Sturrock

(15 January, pp 132-3) may have confused readers. Firstly, we should have converted the target urate level cited in the final paragraph to SI units: the level should have appeared as 250-450 $\mu \mathrm{mol} / \mathrm{l}$ (not $40-70 \mathrm{mg} / \mathrm{l})$. Secondly, some of our younger readers might have been puzzled by the word "podagra" in the first paragraph. The term "gouty pain in the great toe" might have been clearer. 